\title{
Cultural Turn of Translation Studies and Its Future Development
}

\author{
Lisheng Liu \\ School of Foreign Languages, Shandong University, Jinan, China 250100; \\ School of Foreign Languages, Xuchang University, Xuchang, Henan, 461000 \\ E-mail: kevinlls@163.com
}

\begin{abstract}
The cultural turn in 1990s of translation studies is characterized by distinct cultural awareness and deconstructionist academic thought. The paper analyses its characteristics and restrictions, and its future paradigm development in order to have a better understanding of translation studies.
\end{abstract}

Index Terms - cultural turn, future development, translation studies

\section{INTRODUCTION}

The School of Translation Studies has always focused on the study translation issues from cultural perspective, with their own distinctive cultural awareness. Since the term cultural turn of Translation Studies proposed by Snell-Hornby was advocated by Bassnett and Lefevere in the anthology of "translation, history and culture" compiled in 1990, the school of Translation Studies began to tackle translation problems from their different cultural perspectives and formed different theories of translation studies. The famous translation theorist Snell-Hornby in "Translation Studies: An Integrated Approach" enthusiastically describes a culture-oriented translation theory and points out that translation is a cross-cultural communication activities; Susan Bassnett and AndréLefevere introduces many new concepts, including "history", "function" and "Rewriting" in Translation Studies and claims that translation should adapt to cultural requirements; André Lefevere's theory of "patronage, poetics and ideology" investigates translation by putting literary system into the larger social and cultural context to analyse the constraints on the translation mechanism and norms that translators abide by describing different translation phenomenon. The translation studies is intensified by the subsequent feminist translation studies which purport to construct the feminist discourse and the postcolonial translation studies which take the cultural hegemony and cultural identity as its object. All of these approaches of translation studies don't treat translation as static, but a cultural transmission activity constrained by the outer factors, which extremely widen the horizon of translation studies to promote its academic growth. Therefore, it is necessary to analyse the causes, effects, its advantages and limitations in order to have a clear understanding of translation studies.

\section{CUltural TURn IN TRAnsLation StUdies}

\section{A. The Related Causes}

Translation Studies is an empirical, synthetic discipline, taking the translation process and translation products as its study object with the distinct characteristic of integrating the study of related disciplines of linguistic, literature, cultural history, philosophy and anthropology, etc. (Bassnett,1991) The open and interdisciplinary nature of Translation Studies determines the academic integration with the cultural study, whose object covers the political science, history, media studies, literature and cultural theories and other related disciplines. The interdisciplinary nature of cultural study shows its impact on human disciplines which extends to its subdiscipline of Translation Studies. In the aspect of research method, the School of Translation Studies is not restricted to the use of traditional linguistic research model, on the contrary, it puts the study object into the wider social and historical context to study the constraints placed on the translators and the norms that translators abide by in their translation activities. The current academic research conducted from the deconstructionist perspective popular in translation studies and cultural studies make their study object closer to each other, leading to their final integration.

The scholars from the School of Translation Studies acquires a distinct cultural awarenes since the beginning of their research in this area. For example, James Holmes claimes that the study of poetry characteristics are not an issue of linguistics, but of literature and social cultures when he talks about the diachronic elements in poetry translation. Susan Basssnett makes a detailed explanation about one of the four areas of translation studies, i.e. translation in the target culture. Snell-Hornby regards translation as a cross-cultural communication and language is a closely-related part of culture in his work Translation Studies: An Integrated Approach. The Polysystem theory proposed by Even-Zohar investigated the role played by translated literature with the wider social system of culture. Toury analyses the various norms influencing translation activities within the theoretical framework of polysystem, from the perspective of operational norms, the translator's decision is restricted by the position of translated literature within the target cultural polysystem (Gentzler, 2001). Later on, André Lefevere, Lambert and Theo Hermans studies translation purely from the 
cultural perspective to investigate the external factors influencing the translator's decision and the role of translated works within the target culture, all the researches mentioned above contributed to the cultural turn of translation studies.

\section{B. The Cultural Turn of Translation Studies}

Susan Bassnett and André Lefevere as the advocate of cultural turn of translation studies plays a leading role in the novel research paradigm, together with the theory of "patronage, poetics and ideology" proposed by André Lefevere, it contributes greatly to the theoretical development of translation studies from the cultural perspective. Within this paradigm, translation is regarded as rewriting which can introduce new concepts, genres, techniques and motifs, etc. as explained in the famous book Translation, Rewriting and the Manipulation of Literary Fame. Therefore, the history of translation is one of literary innovation and one of shaping one culture by another. André Lefevere claims that literary system is a cultural activity which is constrained by dual mechanism which consists of the professionals coming from the inner cultural system like critics, reviewers, teachers and translators themselves; the patronage outside the literary system which includes the powers that can further or hinder the reading, writing, and rewriting of literature, by patronage, Lefevere means "any kind of force that can be influential in encouraging and propagating, but also in discouraging, censoring and destroying works of literature."(Gentzler, 2004) the patronage is referred to as differentiated or undifferentiated. The third factor is the dominant poetics including the literary devices and the concept of the role of literature. André Lefevere makes the claim on the action between poetics, ideology and patronage in translation that "on every level of translation process, it can be shown that, if linguistic consideration enters into conflict with consideration of an ideological and/or poetological nature, the latter tend to win out."(1993:39) This approach is intensified by the following feminist and postcolonial translation studies in 1990s, with the former beginning to examine the social-cultural processes that determined woman's inferior status in society and then to shift focus to examinations of the ways language itself is a means by which women have been relegated to an inferior status, silencing their artistic expression in literary works. The feminists see a parallel between the status of translation and that of women who were always repressed in their society and literary works. Therefore, feminist approach to translation studies began to identify and criticize the concepts that relegates women and translation to the bottom of social and literary ladder, and examine the processes through which translation sustains the gender construct. The approach taken to address the issue is through reevaluation of translations, interventionist methods, interrogation of gender terms and linguistic constructions, etc. to address the social stereotypes embedded in the linguistic forms of literary works.

The postcolonial approach to translation studies with Spivak, Niranjana, Susan Bassnett and Trivedi as the advocate began to analyse the asymmetrical power relations in the postcolonial context. The linking of colonization and translation is accompanied by the argument that translation has played an active role in the colonization process and in propagating an ideologically motivated image of the colonized peoples. Niranjana in her book Sitting Translation discusses the inequalities between languages, cultural domination and manipulative power of translation which sheds light on the role of translation in establishing representation of the colonial subject with the post-colonial context. According to them, translation has long been a site for perpetuating the unequal power relations among peoples, races ad languages. The different approaches within the cultural perspectives widen the scope of translation studies and propelled it to a higher status and prosper in 1990s.

\section{Comment on Cultural Turn of Translation Studies}

Cultural Turn in Translation Studies as an external study results from the development of western academic thinking trend, and it reveals its nature as a cultural activity and widen its research scope to deviate the static linguistic analysis by comparing original work and translated works, giving a true picture of the translation activity which took place in their special spatial-temporal context. The study of translation activity from the cultural perspective can comprehensively examine the external factors and function and influence of translation in the target literary system. However, there is trend of regarding the cultural approach of translation studies as the whole while overlooking the linguistic analysis when it widens it study scope to incorporate external factors by surpassing the linguistic approach. In fact, the analysis of the cultural factors influencing translation activity must be based on the translated works, i.e. the linguistic aspect which is regarded as a basis, just as the new version proposed that "Translation is a translingual and cross-cultural communicative activity by taking linguistic transformation as the basic means and meaning recreation as the basic task."(Xu Jun, 2003) the above definition clearly shows that the analysis of translated works from any perspective must not be divorced from the text itself of literary works, the widening scope which can reveal the nature of translation more accurately cannot deny the linguistic aspect of translation, i.e. inner study, especially the research on the psychology of translators, the decisions made by them when facing difficult text, their translation competence and its constituents and interaction to raise the competence to a higher level, all these aspects predicates on the integration of the different approaches to translation studies to complement instead of contradicting each other, to take a equal-balanced approach by combining them to give impetus to translation studies, for which Snell-Hornby's approach is a thought provoking attempt.

\section{ANALYSIS OF TRANSLATION PARADIGMS}

\section{A. Traditional Translation Paradigm}


"Science is not the simple accumulation of facts, theory and methods, or its development of accumulation of knowledge but a continuous progressive progress of paradigm transformation.”(Wu Xiaoying, 2000) Paradigm is not only the prerequisite of scientific research, but the marker of scientific maturity. The development of translation studies brings forth the evolution of paradigms which provide the theoretical assumption, research model, research method and judging criteria, etc. the old paradigm is always replaced by the new ones, which consequently prompts the development of translation studies to establish itself as an independent discipline. The translation studies in China and abroad can be generally divided into three phases: philological paradigm, structuralist paradigm and deconstructionist paradigm(Lv Jun,2001) The traditional translation studies before 1950s can be classified into the philological paradigm because there was no systematic analysis of translation theory and it only talked about the concrete translation techniques and abstract translation principles. The translation theories were characterized by impressionistic, subjective and asystematic comment which focused on translator's enlightenment and understanding, their personal experiences. The following structuralist theory emphasized the analysis of text to examine the laws of linguistic transformation and the models for equivalent effects which put the translation study out of impressionistic stranglehold. At the same time, it was only concerned with the inner structure of text itself while neglecting the external factors influencing translation activities, the outlook of regarding translation as a close process brought translation study to an impasse. The translation studies from 1990s, especially after the cultural turn took the deconstruction as its theoretical basis and denounced the logocentrism to analyse the macro factors like socio-historical context, ideology, power discourse, etc. to widen greatly the scope of translation studies. Different multi-dimensional, multi-disciplinary approaches thrived in translation studies leading to a trend of cultural determinism in translation while overlooking the linguistic aspects and regarding the cultural studies as the whole, which turns the translation study upside down and is detrimental to its later development.

\section{B. The Future Development Trend}

It is imperative for us to have a better understanding of the current trends of translation studies and its future development trend to deal with the different approaches and give an accurate positioning of cultural studies. Translation is in essence a thinking process which takes place within the translator's mind by taking the linguistic and cultural factors into consideration. Any description of translation or stipulation of translation principles must at last be traced to the translator's behavior, which brings the transformation of source text into the target text. The infinite widening of cultural studies of translation studies can make the analysis empty and deprive its essence. The future development requires the combination of different approaches and at the same time all the analysis must be focused on the translator's translation process. The reductionist approach is different from the traditional translation studies which focus on the text and writers, it focuses on the translator's behavior, the inner process of translation, which requires the knowledge of computer science, cognitive linguistics, psycho-linguistics and corpus linguistics, etc. Translator's translation competence needs to be convincingly analysed so as to promote the training of translators and give an explanation of translation behavior which is influenced by the internal and external factors. "We must be able to explain (a translation) and its mechanism of thinking. The current translation teaching has been following a procedure which is established on the incomplete, even wrong understanding of translation concept."(Lin Kenan:2000) The accurate understanding of translator's thinking mechanism can further promote the development of computer-aided translation based on corpus, which provides important resources for comparative translation studies, lexicography and translator training, etc consequently the combination of cultural approach with linguistic approach which focus on translator's behavior will bring new breakthrough for translation studies in the future.

\section{CONCLUSION}

Cultural Turn in Translation Studies reveals cultural attributes of translation and widens the its research scope. However, it overlooks the linguistic aspects and regards the external study as the whole of translation studies, which tend to make the translation study culture-determined and become a means of cultural analysis by turning the focus upside down. The future paradigm requires a better understanding of the inner relations between the different approaches to integrate them into a coherent whole and focus on the translator's behavior to better understand the nature of translation.

\section{REFERENCES}

[1] Bassnett, Susan. Translation Studies. London and New York:Routledge, 1991.

[2] Gentzler, Edwin. Contemporary Translation Theories. Clevedon: Multingual Matters Ltd.,2001

[3] Gentzler, Edwin. Contemporary Translation Studies. London: Routledge, 1993; $2^{\text {nd }}$ edition,2001; Shanghai: SFLEP,2004.

[4] Lefevere, André, Translation, Rewriting and Manipulation of Literary Fame. London: Rotledge, 1993.

[5] Lin Kenan, Translation teaching overseas. Chinese Translators Journal, 2000,(2)

[6] Lv Jun. Overcoming Cultural Barriers-Reconstruction of Babel. Dongnan University Press, 2001

[7] Niranjana, Tejaswini. Siting Translation: History, Post-structurism, and the Colonial Context. Berkeley: University of California Press, 1992.

[8] Wu Xiaoying, Science, Culture and gender. Chinese Social Science Press, 2000

[9] Xu Jun. On Translation. Hubei Educational Press, 2003 